ARTICLE OPEN

\title{
Large hemispheric differences in the Hadley cell strength variability due to ocean coupling
}

\author{
Rei Chemke iD ${ }^{1 凶}$
}

By modulating the distribution of heat, precipitation and moisture, the Hadley cell holds large climate impacts at low and subtropical latitudes. Here we show that the interannual variability of the annual mean Hadley cell strength is $\sim 30 \%$ less in the Northern Hemisphere than in the Southern Hemisphere. Using a hierarchy of ocean coupling experiments, we find that the smaller variability in the Northern Hemisphere stems from dynamic ocean coupling, which has opposite effects on the variability of the Hadley cell in the Southern and Northern Hemispheres; it acts to increase the variability in the Southern Hemisphere, which is inversely linked to equatorial upwelling, and reduce the variability in the Northern Hemisphere, which shows a direct relation with the subtropical wind-driven overturning circulation. The important role of ocean coupling in modulating the tropical circulation suggests that further investigation should be carried out to better understand the climate impacts of ocean-atmosphere coupling at low latitudes.

npj Climate and Atmospheric Science (2022)5:1; https://doi.org/10.1038/s41612-021-00225-3

\section{INTRODUCTION}

The Hadley circulation plays a central role in controlling the meridional distribution of temperature, humidity, and precipitation at low latitudes. Thus, changes in the strength and position of the Hadley cell have large climate impacts in tropical and subtropical regions. For example, the projected weakening of the Northern Hemisphere $(\mathrm{NH})$ Hadley cell and widening of the Southern Hemisphere (SH) Hadley cell in coming decades will affect the strength and position of the hydrological cycle both at semi-arid regions and in the deep tropics ${ }^{1-4}$. On shorter timescales, the interannual variability of the Hadley cell was argued to modulate the equatorial atmospheric heat transport, the location and strength of the Inter-Tropical Convergence Zone (ITCZ), and the activity of tropical cyclones ${ }^{5-7}$.

While changes in the Hadley cell over different timescales may stem from different mechanisms ${ }^{4,8}$, over a wide range of timescales, ocean coupling was argued to affect the Hadley cell's behavior. For example, on intraannual timescales dynamic ocean coupling (i.e., the effect of changes in ocean heat flux convergence, OHFC) was found to weaken the tropical circulation and to generate the strong asymmetry between the summer and winter tropical circulations and precipitation'. On multidecadal timescales, OHFC was found to reduce the projected (by 2100) weakening of the circulation by $\sim 60 \%$ (via both horizontal ocean heat transport and vertical heat uptake) and the widening of the circulation by $30 \%$ (mostly via oceanic heat uptake) ${ }^{10,11}$. Similarly, via ocean coupling processes, the projected melting of Arctic sea ice by the end of this century was shown to have a significant effect on the Hadley cell. In response to the projected sea-ice loss, while thermodynamic ocean coupling was found to expand and weaken the Hadley cell, dynamic coupling was found to contract and strengthen the circulation ${ }^{12-14}$.

On interannual timescales, previous studies suggested that ocean coupling also plays an important role in the Hadley cell's variability. For example, the El Nino-South Oscillation (ENSO) was argued to affect the interannual variability of both the Hadley cell width $^{15-18}$ and strength ${ }^{19-24}$, mostly over the Pacific, and mostly the symmetric component of the circulation around the equator. It should be noted that mid-latitude eddies were also argued to affect the variability of the Hadley cell strength, mostly in the $\mathrm{NH}^{24-26}$.

Interestingly, using NCEP reanalysis, the interannual variability of the $\mathrm{NH}$ Hadley cell strength was shown to be smaller than the variability of the $\mathrm{SH}$ Hadley cell strength ${ }^{27}$. This hemispheric difference deserves further investigation, as not only it breaks the expected hemispheric symmetry in the atmospheric flow, but it also points to the different climate impacts of the Hadley cell variability in the two hemispheres; recall that the Hadley cell strength has a large effect on the precipitation intensity over the ascending and descending branches of the circulation, and on the temperature distribution in the tropics. A leading potential process to explain any hemispheric difference in the large-scale atmospheric flow is ocean coupling. Thus, given the important role of ocean coupling in the Hadley cell strength variability, we here examine the role of ocean coupling in the different hemispheric variability of the Hadley cell strength. In particular, we revisit this hemispheric difference, corroborate its existence using multiple reanalyses and state-of-the-art climate models, and use a hierarchy of ocean coupling experiments. Such hierarchy allows us to investigate and better understand the relative roles of ocean coupling, and its dynamic and thermodynamic components, in the different variability of the circulation in the two hemispheres.

\section{RESULTS}

Quantifying the role of ocean coupling in the different hemispheric Hadley cell's variability

We start by assessing the different interannual variability in the annual mean $\mathrm{SH}$ and $\mathrm{NH}$ Hadley cell strength $\left(\Psi_{\max }\right.$, Methods) over recent decades in the Coupled Model Intercomparison Project Phase 5 (CMIP5) and Reanalyses (Methods). This is done by calculating the difference between the variance of the detrended $\mathrm{NH}\left(\sigma_{\mathrm{NH}}^{2}\right)$ and $\mathrm{SH}\left(\sigma_{\mathrm{SH}}^{2}\right) \Psi_{\max }$ time series over 1979-2017, relative

\footnotetext{
${ }^{1}$ Department of Earth and Planetary Sciences, Weizmann Institute of Science, Rehovot, Israel. ${ }^{凶}$ email: rei.chemke@weizmann.ac.il
} 
a

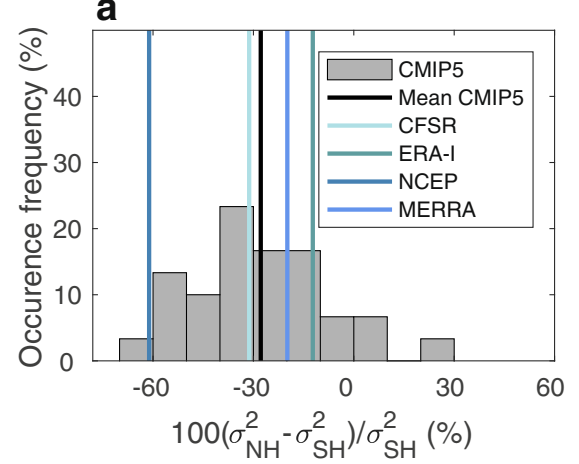

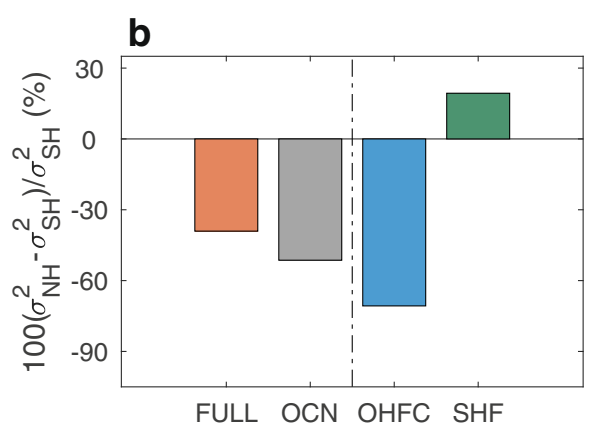

Fig. 1 Hemispheric difference in the Hadley cell variability and the role of ocean coupling. a The occurrence frequency (in percentage) of the difference in the variance of $\Psi_{\mathrm{max}}$ in the $\mathrm{NH}\left(\sigma_{\mathrm{NH}}^{2}\right)$ and $\mathrm{SH}\left(\sigma_{\mathrm{SH}}^{2}\right)$ (in percentage) over the 1979-2017 period in CMIP5 models (gray bars). Black and blue vertical lines show the difference in the variance between the hemispheres in CMIP5 mean and reanalyses, respectively. $\mathbf{b}$ The difference in the variance of the $\mathrm{NH}$ and $\mathrm{SH} \Psi_{\max }$ in the FULL run (red bar). The relative contribution to the difference in the variance from ocean coupling (gray bar, OCN) and from decomposing the ocean coupling to dynamic coupling (OHFC, blue bar) and thermodynamic coupling (SHF, green bar).

to $\sigma_{\mathrm{SH}}^{2}$. Almost all CMIP5 models (27 out of 30 , gray bars in Fig. 1a) show that $\sigma_{\mathrm{NH}}^{2}$ is smaller than $\sigma_{\mathrm{SH}}^{2}$, with a multi-model mean value of $-28 \%$ (vertical black line). Similarly, all reanalyses show that the $\Psi_{\max }$ variability in the $\mathrm{NH}$ is smaller than the variability in the $\mathrm{SH}$, with a mean value of $-31 \%$ (vertical blue lines in Fig. 1a); in CFSR, Era-Interim, NCEP and MERRA $\sigma_{\mathrm{NH}}^{2}$ is smaller than $\sigma_{\mathrm{SH}}^{2}$ by $31 \%, 12 \%$, $61 \%$, and $20 \%$, respectively. Note that the smaller Hadley cell strength variability in the $\mathrm{NH}$, relative to the $\mathrm{SH}$, is not only evident at the location of $\Psi_{\max }$, but throughout the tropics (Supplementary Fig. 1). These results corroborate the finding of previous studies, which also found using NCEP reanalysis, larger variability in the SH Hadley cell than the NH Hadley cell ${ }^{27}$.

To investigate the role of ocean coupling in the different interannual variability of $\Psi_{\max }$ in the two hemispheres using a longer dataset, and in the absence of a transient external forcing (i.e., where only the internal variability of the circulation is present), we follow previous studies ${ }^{11,28,29}$ and analyze a hierarchy of ocean coupling simulations in long preindustrial control runs (Methods). In particular, using the Community Earth System Model (CESM), we analyze the effects of the different components in the oceanic mixed-layer temperature equation, $\rho c_{p} h \frac{\partial T}{\partial t}=\mathrm{SHF}+\mathrm{OHFC}$, where, $\rho$ is sea-water density, $c_{p}$ is the ocean specific heat capacity, $h$ mixed-layer depth, $T$ is temperature, SHF represents the net heat flux into the ocean from the atmosphere/sea-ice (thermodynamic coupling), and OHFC is dynamic coupling $(-\nabla \cdot(\boldsymbol{v} T)$, where $\boldsymbol{v}$ is the velocity vector).

The first simulation (hereafter referred to as FULL) uses the fullycoupled configuration, including a full-physics ocean, of CESM ${ }^{30}$, where both thermodynamic and dynamic coupling are active. In the second simulation $^{30}$ (hereafter referred to as SOM), while interannual variability of thermodynamic coupling is active, the interannual variability of dynamic ocean coupling is inactive; OHFC and $h$ are fixed at their preindustrial values (Methods). Thus, comparing the FULL and SOM runs allows inferring the effects of dynamic ocean coupling on the interannual variability of the Hadley cell. Fixing the OHFC and mixed-layer depth is done by replacing only the full-physics ocean component in FULL with a slab-ocean model (SOM); from an atmospheric perspective, the sole difference between the FULL and SOM is the variability of dynamic ocean coupling. In the third simulation (hereafter referred to as NOM), both thermodynamic and dynamic coupling are inactive, as the sea surface temperature in the slab-ocean model is fixed at its preindustrial values (there is no active ocean model, NOM). Thus, while comparing the FULL and NOM simulations isolates the net role of ocean coupling in the interannual variability of the Hadley cell, comparing the SOM and NOM runs allows isolating the role of thermodynamic coupling (see Methods for more information on the FULL, SOM, and NOM simulations). The comparison of the simulations allow us to investigate the role of each ocean coupling component in the Hadley cell variability, including indirect effects of ocean processes via other climate system components; i.e., any effects on the Hadley cell variability that involve ocean coupling. Lastly, note that such attribution analysis relies on the fact that the effects of ocean coupling are linearly additive; by construction, the sum of the roles of dynamic and thermodynamic coupling yields the net role of ocean coupling as inferred from the fixed mixed-layer temperature run.

Similar to the $\Psi_{\max }$ variability in reanalyses and CMIP5 models, in the FULL run $\sigma_{\mathrm{NH}}^{2}$ is $39 \%$ smaller than $\sigma_{\mathrm{SH}}^{2}$ (red bar in Fig. 1b). This provides us the confidence to use the CESM preindustrial runs to investigate the role of ocean coupling in the different variability of $\Psi_{\max }$ in the two hemispheres. Note that here we focus on the annual mean Hadley cell variability, in order to eliminate the effects of the seasonal cycle on the relation between ocean coupling processes and the Hadley cell strength (e.g., the single winter cells), thus to focus only on the effect of the interannual variability of the ocean on the Hadley cell's variability in the two hemispheres. Nonetheless, below we further discuss the results during March-May (MAM) and September-November (SON), where two Hadley cells are evident concomitantly, as in the annual mean.

First, we focus on the net role of ocean coupling (i.e., the different variability in the FULL and NOM runs). Ocean coupling results in an interannual variability of $\Psi_{\max }$ in the $\mathrm{NH}$ that is $51 \%$ less than the interannual variability in the SH (gray bar in Fig. 1b). Thus, the interannual variability of the ocean is responsible for the smaller variability in the $\mathrm{NH}$ relative to the $\mathrm{SH}$; without an active ocean, the variability of the circulation would have been larger in the $\mathrm{NH}$ than the SH. Further decomposing the effect of ocean coupling to thermodynamic (i.e., the different variability in the SOM and NOM runs) and dynamic (i.e., the different variability in the FULL and SOM runs) coupling reveals that dynamic coupling (i.e., changes in OHFC) is responsible for the smaller variability of the Hadley cell in the $\mathrm{NH}$; OHFC changes result in variability of the $\mathrm{NH}$ Hadley cell that is $70 \%$ less than the variability in the $\mathrm{SH}$ (blue bar in Fig. 1b). This effect of dynamic coupling overcomes the relative minor tendency of surface heat fluxes (SHF, i.e., thermodynamic coupling) to produce a larger variability in the $\mathrm{NH}$ (by 20\%) relative to the $\mathrm{SH}$ (green bar in Fig. 1b).

Before further investigating the role of OHFC in the different variability in the two hemispheres, we ensure that the effect of dynamic coupling to produce the smaller variability in the $\mathrm{NH}$ 

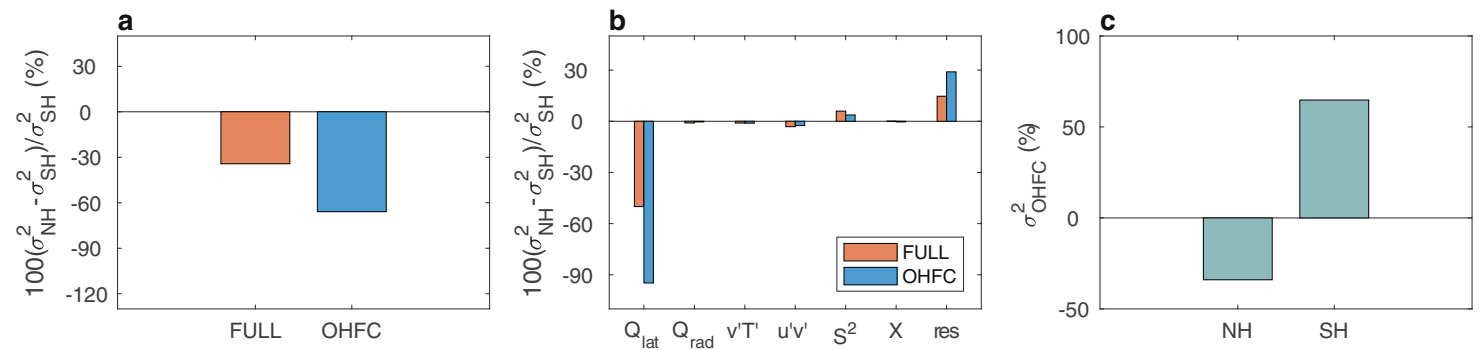

Fig. 2 Dynamic coupling and the different hemispheric Hadley cell variability. a The difference in the variance of the NH and SH Hadley cell strength (in percentage), calculated using the KE equation $\left(\Psi_{\max }^{\mathrm{KE}}\right)$, in the FULL run (red bar) and the relative contribution from OHFC (blue bar). b The relative contribution to the difference in the variance (in percentage) from latent heating $\left(Q_{\text {lat }}\right)$, radiative heating $\left(Q_{\text {rad }}\right)$, eddy heat flux $\left(v^{\prime} T^{\prime}\right)$, eddy momentum flux $\left(u^{\prime} v^{\prime}\right)$, static stability $\left(S^{2}\right)$, zonal friction $(X)$, and a residual (res). $c$ The relative contribution of OHFC (in percentage) to the variance of the $\mathrm{NH}$ and $\mathrm{SH} \Psi_{\max }^{\mathrm{KE}}$.

Hadley cell, relative to the SH Hadley cell, is not dependent on the specific formulation of the CESM. This is done by comparing the variability of the Hadley cell in two preindustrial runs using the full and slab ocean configurations of GISS Model E2.1 (Methods). Similar to the role of OHFC in CESM, in GISS Model E2.1, dynamic coupling is responsible for the smaller (by $\sim 53 \%$ ) variability of the Hadley cell in the $\mathrm{NH}$, relative to the $\mathrm{SH}$ (Supplementary Fig. 3); without dynamic ocean coupling, the $\mathrm{NH}$ and $\mathrm{SH}$ Hadley cells in GISS would have shown similar interannual variability. This provides us the confidence that the role of ocean coupling to result in the large hemispheric differences in the Hadley cell variability is not dependent on the specific formulation of the CESM.

\section{Investigating the role of ocean dynamic coupling in the different Hadley cell's variability in two hemispheres}

We next investigate via which mechanisms OHFC gives rise to the smaller variability of the circulation in the $\mathrm{NH}$, relative to the $\mathrm{SH}$. This is done by calculating the Hadley cell strength from the solution of the Kuo-Eliassen (KE) equation ( $\Psi_{\max }^{\mathrm{KE}}$, Methods). The KE equation is an elliptic equation for the meridional mass stream function $(\Psi)$ and takes the simple form, $L \Psi=D_{Q_{\text {lat }}}+D_{Q_{\text {rad }}}+$ $D_{\overline{v^{\prime} T^{\prime}}}+D_{\overline{u^{\prime} v^{\prime}}}+D_{X}$, where the operator $L$ is a function of static stability and the Coriolis parameter, and the righthand side terms account for the effects of latent heating $\left(D_{\mathrm{O}_{\mathrm{lat}}}\right)$, radiative heating $\left(D_{Q_{\mathrm{rad}}}\right)$, eddy heat $\left(D_{v^{\prime} T^{\prime}}\right)$ and momentum $\left(D_{u^{\prime} v^{\prime}}\right)$ fluxes and zonal friction $\left(D_{X}\right)$ (See Methods for a full description of these terms, and a discussion on the interpretation of the results from the KE equation analysis). Using the solution of the KE equation in the FULL and SOM runs, we analyze the roles of the different components in the KE equation in modulating the variability of the circulation in the two hemispheres via OHFC processes. Note that due to the fact that in annual mean, the different terms in the $\mathrm{KE}$ equation are not independent, the effect of each term on the annual mean circulation might stem from the changes in other terms in the equation; in particular, from eddy fluxes ${ }^{31,32}$.

Before analyzing the KE equation, we verify that $\Psi_{\max }^{\mathrm{KE}}$ adequately captures the variability of $\Psi_{\max }$ in the FULL and SOM runs. First, $\Psi_{\max }$ and $\Psi_{\text {max }}^{\mathrm{KE}}$ are highly correlated across all years in each run (Supplementary Fig. 4), in both the $\mathrm{NH}$ (with $r=0.93$ and $r=0.96$ in the FULL and SOM runs, respectively), and in the $\mathrm{SH}$ (with $r=0.98$ and $r=0.98$ in the FULL and SOM runs, respectively). Second, similar to $\Psi_{\max }$, not only that $\psi_{\max }^{\mathrm{KE}}$ captures the smaller variability in the $\mathrm{NH}$, relative to the $\mathrm{SH}$ (by $34 \%$, red bar in Fig. 2a), it also captures the role of OHFC in driving the different variances in the two hemispheres (dynamic ocean coupling results in $65 \%$ less $\Psi_{\max }^{\mathrm{KE}}$ variability in the $\mathrm{NH}$, relative to the $\mathrm{SH}$, blue bar). These validations provide us the confidence to use the KE equation to investigate the mechanisms underlying the hemispheric differences in the variability of $\Psi_{\max }$.
The linearity of the KE equation allows one to examine the roles of each of the righthand side terms, along with static stability (the operator on the lefthand side), in modulating the circulation. This is done, following previous studies ${ }^{8,11,33,34}$, by rewriting the KE equation as, $L \Psi=D$, where $D$ is the sum of the righthand side terms. Decomposing $L, \Psi$, and $D$ to their mean preindustrial value and deviation from it, yields the following equation for the deviations of $\Psi(\delta \Psi), L_{\text {mean }} \delta \Psi=\delta D-\delta L \Psi_{\text {mean }}-\delta L \delta \Psi$, where $\delta D$ and $\delta L \Psi_{\text {mean }}$ isolate the contributions from each of the righthand side terms in the KE equation and from static stability to $\delta \Psi$, respectively, and $\delta L \delta \psi$ represents the multiplicative deviations in static stability and in $\Psi$ (calculated as a residual). The contribution of each term to the variance of the circulation is estimated at the location of $\Psi_{\mathrm{max}}^{\mathrm{KE}}$, such that their sum yields the variance in $\psi_{\mathrm{max}}^{\mathrm{KE}}$. Note that since the variance is calculated using the square of $\delta \Psi$, not only the square of each term on the righthand side affects the variance of the circulation, but also the product of all other possible pairs $\left(\left.\delta \Psi\right|_{\text {product }}\right)$.

The relative contribution to the hemispheric difference in the variance of the circulation from each of the righthand side terms in the KE equation, static stability $\left(S^{2}\right)$ and a residual $(\delta L \delta \Psi$ and $\left.\left.\delta \Psi\right|_{\text {product }}\right)$ is shown in Fig. 2 b. First, in the FULL run (red bars), the term that mostly contributes to the smaller variability of $\Psi_{\max }^{\mathrm{KE}}$ in the $\mathrm{NH}$, relative to $\mathrm{SH}$, is the meridional gradient of latent heating $\left(Q_{\text {lat }}\right)$. All other terms either have a minor effect on the variability difference between the two hemispheres (e.g., radiative heating, eddy fluxes, static stability, and friction), or result in a larger variability in the $\mathrm{NH}$, relative to the $\mathrm{SH}$ (e.g., residual; the relatively large values of the residual terms stem from the interaction of eddy momentum fluxes and static stability with the other terms in the KE equation, Supplementary Fig. 5). Second, the effect of $Q_{\text {lat }}$ on the hemispheric difference in the variance of $\Psi_{\max }^{\mathrm{KE}}$ stems from changes in OHFC (blue bars); without the interannual variability in OHFC, $Q_{\text {lat }}$ would have resulted in a larger variability in the $\mathrm{NH}$ than the $\mathrm{SH}$.

Next, we ask: how does OHFC affect the interannual variability of $\Psi_{\max }$ in each hemisphere via $Q_{\mathrm{lat}}$ ? We start answering this question by isolating the effect of OHFC on the variability of $\Psi_{\max }$ in each hemisphere (Fig. $2 \mathrm{c}$ ). The interannual variability of OHFC has opposite effects on the $\Psi_{\max }$ variability in the two hemispheres; while OHFC changes act to reduce the $\Psi_{\max }$ variability in the $\mathrm{NH}$ (by $35 \%$ ), they act to increase the $\Psi_{\max }$ variability in the $\mathrm{SH}$ (by $65 \%$ ).

To better understand the opposite effects of OHFC on the $\Psi_{\max }$ variability in the two hemispheres, we next explore the interannual changes in the ocean's circulation that are linked to the interannual changes in $\Psi_{\max }$. This is done by regressing the Meridional Overturning Circulation (MOC) against $\Psi_{\max }$ in each hemisphere (from the FULL run). The resulting regression of MOC onto $\Psi_{\max }$ (normalized by $\Psi_{\max }$ climatological value) is shown in Fig. $3 a, b$ (colors), along with the mean preindustrial MOC 

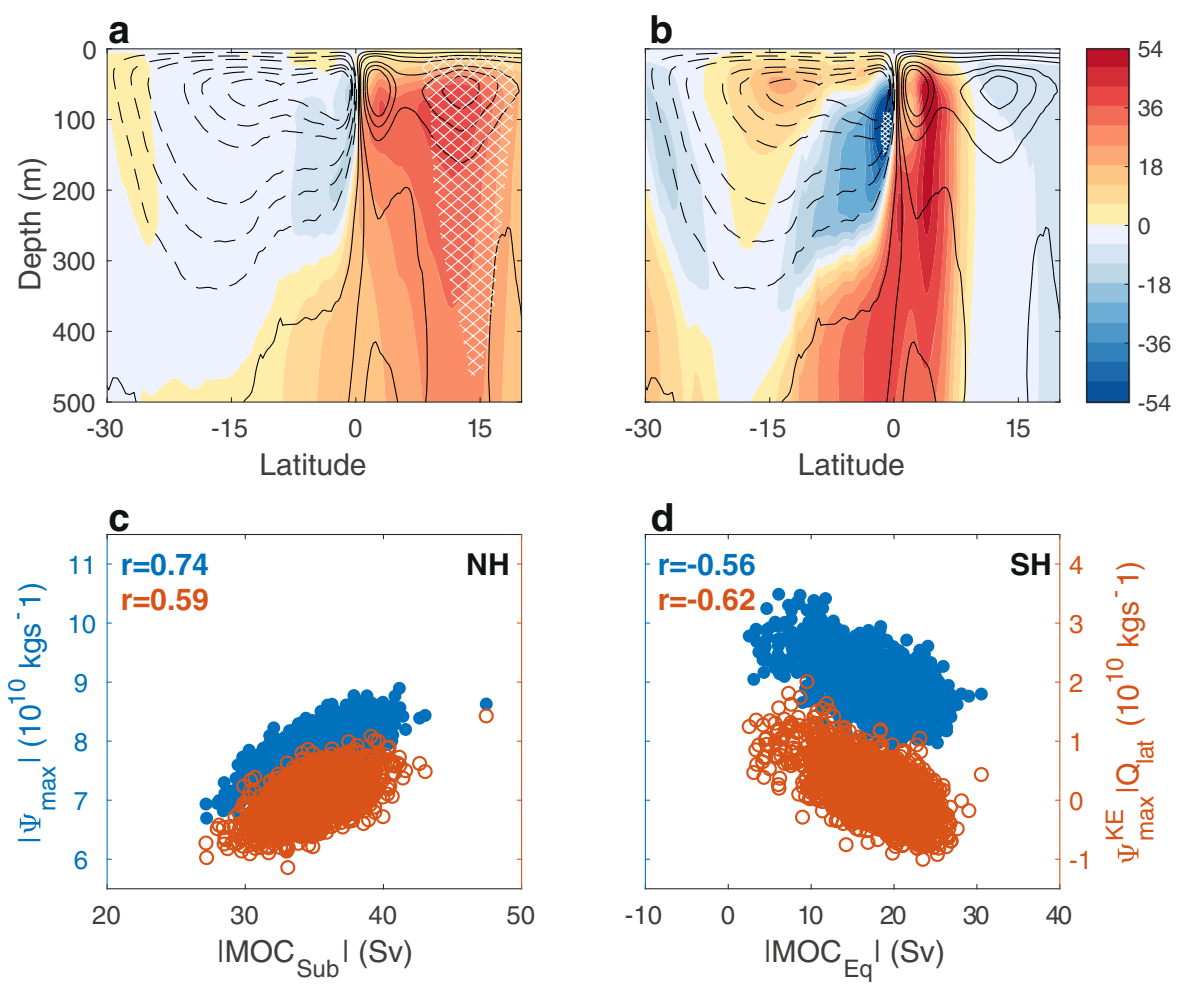

Fig. 3 Linking the MOC to the Hadley cell strength. The regression of the MOC onto $\Psi_{\max }$, normalized by its climatological value (Sv, colors) in the (a) NH and (b) SH. Black contours show the mean preindustrial values of the MOC in intervals of 5 Sv and maximum/minimum values of $\pm 35 \mathrm{~Sv}$. Hatching shows where the MOC is linked to $\Psi_{\max }$ (i.e., with $R^{2} \geq 0.3$ ). c NH $\Psi_{\max }$ (blue, $10^{10} \mathrm{kgs}^{-1}$ ), and the relative contribution from latent heating $\left(\Psi_{\max }^{\mathrm{KE}} \mid Q_{\text {lat }}\right.$, red), plotted against the wind-driven overturning circulation $\left(\mathrm{MOC}_{\mathrm{Sub}}, \mathrm{Sv}\right)$. d Same as in panel (c), only the SH Hadley cell strength plotted against the equatorial upwelling $\left(\mathrm{MOC}_{\mathrm{Eq}}, \mathrm{Sv}\right)$. Correlations are shown in the upper left corners.

(contours). The white hatching shows where the MOC is linked to $\Psi_{\max }$ (where the MOC explains at least $30 \%$ of the $\Psi_{\max }$ variability, i.e., $R^{2} \geq 0.3$ ).

In the $\mathrm{NH}$, the $\Psi_{\max }$ variability is linked to the variability of the subtropical wind-driven overturning circulation (Fig. 3a). Across all years, the strength of the Hadley cell and of the wind-driven overturning circulation (estimated as the maximum of the MOC at the latitude of $\Psi_{\max }$ ) are positively correlated (with $r=0.74$, blue dots in Fig. 3c). Such link between the two circulations is expected since the wind-driven flow stems from the stress exerted by lowlevel easterly winds, which are in balance with the meridional wind in the lower part of the Hadley cell. Namely, off the equator, the Coriolis force on the mean meridional wind balances the frictional force on the mean zonal wind $(u), f \bar{v} \approx r \bar{u}$, where $r$ is a drag constant ${ }^{35}$; poleward of latitude $10^{\circ} \mathrm{N}$ near-surface $f v$ and $u$ are highly correlated, with $r \geq 0.8$ (Fig. 4).

The above relation suggests that as the Hadley cell strengthens (weakens), the oceanic wind-driven flow will act to transfer more (less) heat from low to subtropical latitudes, which may reduce (increase) the meridional gradient of latent heating (via the Clausius-Clapeyron relation), and the strength of the circulation (Fig. 2c). Indeed, the contribution of $Q_{\text {lat }}$ to $\mathrm{NH} \Psi_{\max }^{\mathrm{KE}}$ is also correlated with the strength of the wind-driven overturning circulation (with $r=0.59$, red dots in Fig. 3c). Regressing the sea surface temperature (SST) onto $\mathrm{NH} \Psi_{\max }$ further highlights the damping relation between the wind-driven flow and the Hadley cell since it reveals a pattern of reduction in the meridional temperature gradient (i.e., cooling at low latitudes and warming at subtropical latitudes, which is most evident over the Pacific and to a lesser extent over the Atlantic, Supplementary Fig. 6). This negative effect of the wind-driven flow on $\Psi_{\max }$ was also found to

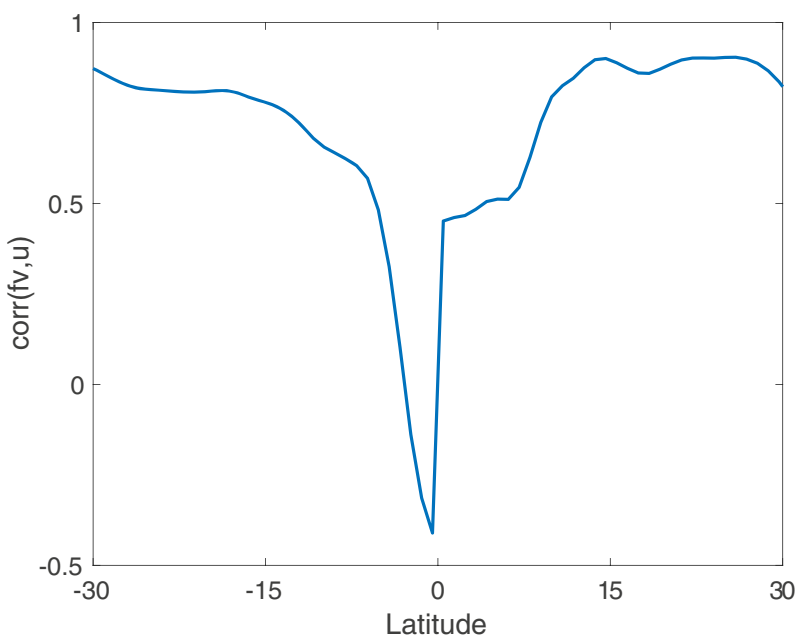

Fig. 4 Linking low-level meridional and zonal winds. Correlation of near-surface Coriolis force on the mean meridional wind $(f v)$ and the mean zonal wind $(u)$ as a function of latitude.

explain the effect of OHFC to reduce the response of the Hadley cell strength to increasing greenhouse gases ${ }^{10,11}$. Note that $\Psi_{\max }$ and the wind-driven flow are positively correlated in spite of the effect of the wind-driven circulation to reduce the changes in $\Psi_{\text {max; }}$ this occurs since OHFC changes merely damp the Hadley cell's strength, thus do not overcome the effect of other processes that set the circulation's strength. 

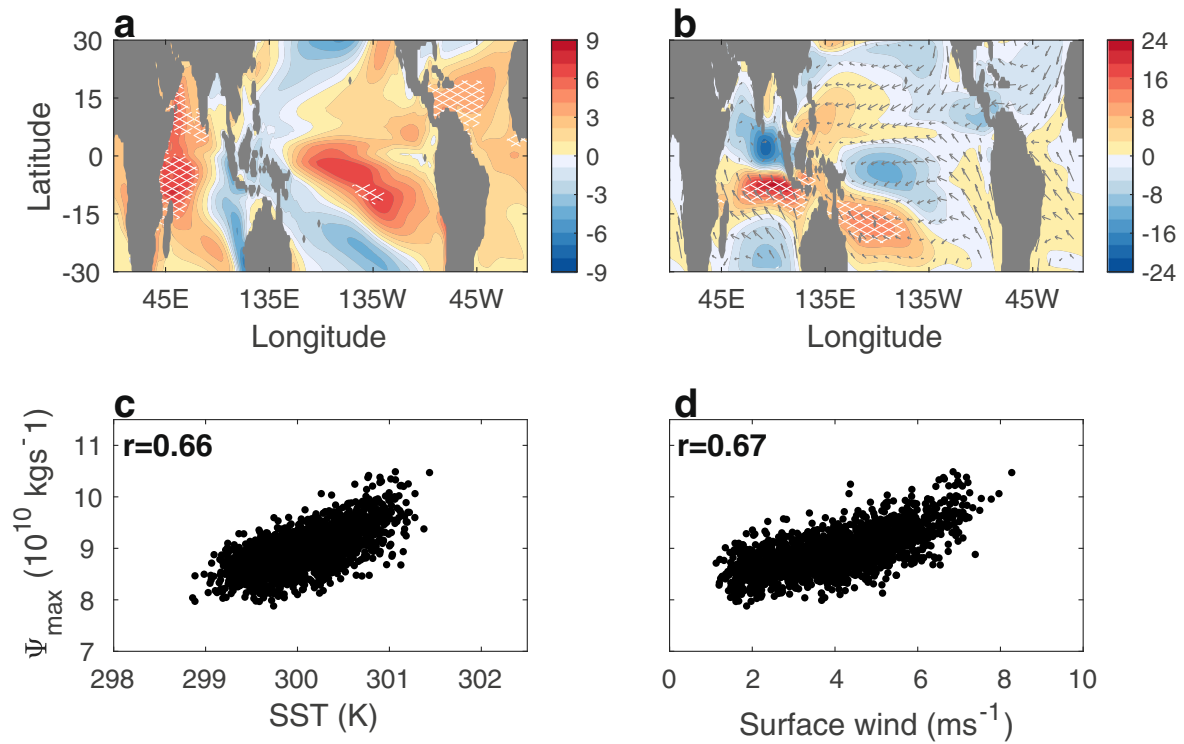

Fig. 5 Linking surface winds and SST to the SH Hadley cell strength. The regression of (a) SST (K, colors) and (b) surface wind vector (ms ${ }^{-1}$, colors) onto SH $\Psi_{\max }$ normalized by its climatological value. Hatching shows where the SST/surface winds are linked to $\Psi_{\max }$ (i.e., with $R^{2} \geq 0.3$ ). The arrows in panel $b$ show the mean surface winds from the FULL run. SH $\Psi_{\max }$ plotted against (c) SST in the Southwest Indian Ocean (K) and (d) surface winds in the Southeast Indian Ocean $\left(\mathrm{ms}^{-1}\right)$ from the FULL run. Correlations are shown in the top left corners.

In the $\mathrm{SH}$, while the balance between the meridional and zonal winds also holds off the equator (with $r \geq 0.7$ poleward of $10^{\circ} \mathrm{S}$, Fig. 4), $\Psi_{\max }$ is only weakly (and positively) linked to the meridional oceanic wind-driven flow (Fig. 3b). Instead, $\Psi_{\max }$ in the $\mathrm{SH}$ is inversely linked to the upwelling branch of the wind-driven flow south of the equator. Thus, unlike in the $\mathrm{NH}$, changes in the upwelling seem to overcome the effect of the meridional wind-driven flow to damp the $\Psi_{\max }$ changes (Fig. 2c). In particular, the strength (in absolute value) of the Hadley cell and of the oceanic upwelling (averaged between $0-2^{\circ} \mathrm{S}$ and between $70 \mathrm{~m}-170 \mathrm{~m}$ ) are negatively correlated (with $r=-0.56$, blue dots in Fig. 3d); as the SH Hadley cell strengthens (weakens) the cooling effect of equatorial upwelling is reduced, which may increase (decrease) the meridional gradient of latent heating, and further increase the circulation (Fig. 2c). Indeed, the contribution of $Q_{\text {lat }}$ to the $\mathrm{SH} \Psi_{\max }^{\mathrm{KE}}$ is also negatively correlated with equatorial upwelling (with $r=-0.62$, red dots in Fig. 3d). The fact that most of the equatorial upwelling occurs within the $\mathrm{SH}$ Hadley cell (recall that the InterTropical Convergence Zone, ITCZ, lies north of the equator) might explain why the $\mathrm{SH}$ circulation, unlike the $\mathrm{NH}$ circulation, is linked to oceanic upwelling. To further corroborate this, note that the larger variability of $\Psi_{\max }$ in the $\mathrm{SH}$, relative to the $\mathrm{NH}$, is also evident during SON when the ITCZ lies north of the equator, while the variability of $\Psi_{\max }$ in the $\mathrm{NH}$ is larger than in the SH during MAM, when the ITCZ lies south of the equator (Supplementary Fig. 7).

To better understand the relation between the SH Hadley cell and equatorial upwelling, which occurs over different regions, we next examine the relation between $\mathrm{SH} \Psi_{\max }$ and SST and surface winds over the different oceanic basins. This is done by regressing the SST (colors in Fig. 5a) and surface winds (colors in Fig. 5b) onto $\Psi_{\max }$ (white hatching shows where the SST/surface winds are linked to $\Psi_{\max }$, i.e., with $R^{2} \geq 0.3$ ). First, in contrast to the NH SST and $\Psi_{\max }$ relation, the lack of cooling at low latitudes and warming at subtropical latitudes even in the Pacific and Atlantic basins (Fig. $5 \mathrm{a}$ ) is in agreement with the weak link between $\mathrm{SH} \Psi_{\max }$ and the meridional oceanic wind-driven flow (Fig. 3b); this suggests that other processes that affect the SST might obscure the relation between the Hadley cell and the wind-driven circulation in the $\mathrm{SH}$. Second, interestingly, while $\Psi_{\max }$ shows positive correlation with SST around the equator over most longitudes, it is most entirely linked to the SST in the West Indian ocean, south of the equator, near the East coasts of Kenya and Tanzania; in this region, most of the upwelling in the South Indian ocean occurs ${ }^{36}$ (unlike in the Pacific and Atlantic oceans, the lack of persistent easterly winds around the equator in the Indian ocean results in off-equatorial upwelling). The high and positive correlation of the SST in the Southwest Indian ocean (averaged between $45-65^{\circ} \mathrm{E}$ and between $1-9^{\circ} \mathrm{S}$ ) with $\mathrm{SH} \psi_{\max }$ (with $r=0.66$, Fig. $5 \mathrm{c}$ ) suggests that a strengthening of the circulation is accompanied with anomalous surface warming, i.e., a reduction in the upwelling and its cooling effect over that region might result in the negative correlation between $\mathrm{SH} \Psi_{\max }$ and zonal mean ocean upwelling (Fig. 3d). Note that although the zonal mean upwelling in Fig. 3d comprises both the equatorial upwelling in the Pacific and Atlantic oceans and the off-equatorial upwelling in the Indian ocean, only the SST in the Indian Ocean seems to be associated with changes in SH $\Psi_{\max }$, which thus affects the relation between $\Psi_{\max }$ and the zonal mean upwelling. One possible reason for the stronger link between SH Hadley cell and SST over the Indian Ocean, than over the Pacific and Atlantic oceans, might be that most of the $\mathrm{SH}$ atmospheric overturning circulation is concentrated over the Indian Ocean ${ }^{37-39}$.

Investigating the relation between $\mathrm{SH} \Psi_{\max }$ and surface winds reveals that, similar to the SST, the SH Hadley cell is linked to the surface winds in the Indian ocean (Fig. 5b; arrows show the mean surface winds from the FULL run). In particular, the Hadley cell is positively correlated (with $r=0.67$, Fig. $5 \mathrm{~d}$ ) with the southeasterly surface winds in the southeast Indian ocean (averaged between $80-100^{\circ} \mathrm{E}$ and between $6-9^{\circ} \mathrm{S}$ ). This surface flow, which is mostly equatorward (as one would expect in the lower branch of the Hadley cell), results in a westward Ekman transport, which may not only carry warm water to the upwelling region in the West Indian ocean, but may also enhance coastal downwelling over the coasts of Africa. These two processes would act to reduce the upwelling and thus its cooling effect over the Southwest Indian ocean, resulting in the inverse and strong relation between the upwelling and $\Psi_{\max }$. Fully elucidating the link between the SH Hadley cell and Indian ocean SST/upwelling is beyond the scope of this paper, but this interesting relation deserves further investigation.

Finally, note that the effect of equatorial upwelling on the $\mathrm{SH}$ Hadley cell strength is different than the Bjerknes feedback mechanism, which links equatorial upwelling and the strength of the Walker circulation over the Pacific ocean ${ }^{40}$. In the Bjerknes 

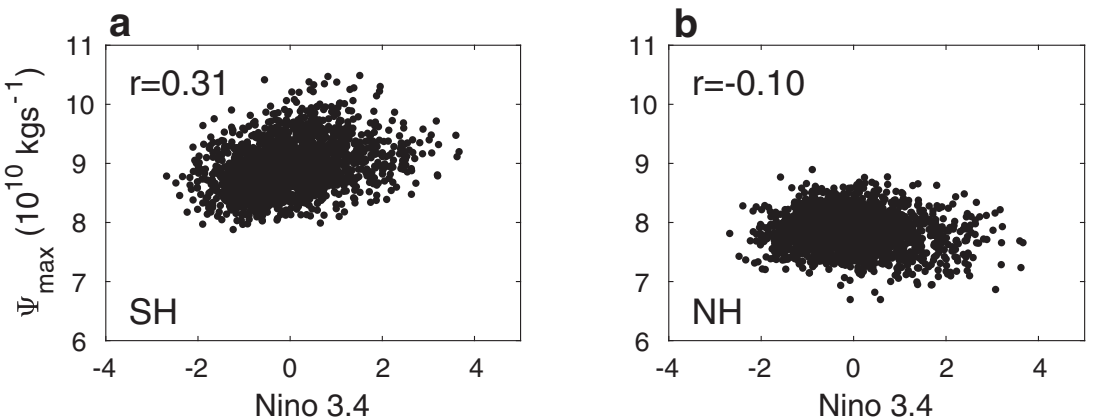

Fig. 6 The relation of ENSO and the Hadley cell strength. (a) SH and (b) NH $\Psi_{\max }$ plotted against Nino 3.4 index from the FULL run. Correlations are shown in the top left corners.

mechanism, enhanced easterlies drive upwelling over the East Pacific, which further increases the easterlies by enhancing the zonal SST gradient. This suggests a positive relation between the Walker circulation and equatorial upwelling. Here, on the other hand, a negative relation is found between the Hadley cell and ocean upwelling, since the mechanism is mostly operative over the Indian Ocean, where the upwelling occurs off-equator in the west parts of the Indian ocean; a stronger southerly flow may thus warm the upwelling region on the west. Furthermore, the link between the variability of the SH Hadley cell and Indian Ocean variability suggests that ENSO variability might be less relevant for modulating the different interannual variability of the Hadley cell's strength in the two hemispheres; ENSO was found to result in a symmetric variability of the circulation around the equator ${ }^{20}$. Indeed, both the $\mathrm{SH}$ and $\mathrm{NH}$ Hadley cells' strength are weakly correlated ( $r=0.31$ and $r=-0.1$ for the $\mathrm{SH}$ and $\mathrm{NH}$ cells, respectively) with the Nino 3.4 index (Fig. 6).

\section{DISCUSSION}

We have here examined the different interannual variability of the Hadley cell strength in the $\mathrm{NH}$ and $\mathrm{SH}$. First, we find that over recent decades, in both reanalyses and CMIP5 models, the variability of the $\mathrm{NH}$ Hadley cell is smaller than the variability in the $\mathrm{SH}$ by $30 \%$. Second, by analyzing a hierarchy of ocean coupling experiments in long preindustrial control runs, we show that the smaller variability of the Hadley cell in the $\mathrm{NH}$ stems from ocean coupling processes. In particular, dynamic coupling (OHFC changes) overcomes the minor effect of thermodynamic coupling (to produce a larger variability in the $\mathrm{NH}$ than the $\mathrm{SH}$ ), and result in the smaller interannual variability of the Hadley cell in the $\mathrm{NH}$ than $\mathrm{SH}$. This occurs as OHFC has opposite effects on the variability of the $\mathrm{NH}$ and $\mathrm{SH}$ circulations. The $\mathrm{NH}$ Hadley cell is directly linked to the meridional wind-driven circulation, which acts to damp the Hadley cell changes. The SH Hadley cell, on the other hand, is inversely related to equatorial upwelling (likely by reducing the upwelling in the Indian Ocean), which enhances the Hadley cell changes.

The effects of the different oceanic components on the Hadley cell strength in the $\mathrm{NH}$ and $\mathrm{SH}$ suggests that the different interannual variability of the Hadley cell strength in the two hemispheres might stem from the fact that the ITCZ lies northward of the upwelling region; as a result of this northward displacement of the ITCZ most equatorial upwelling occurs within the SH Hadley cell. On the other hand, the NH Hadley cell, which, due to its position, is less linked to equatorial upwelling, is mostly affected by the negative effect of the meridional wind-driven circulation. Similarly, while during SON, the ITCZ lies north of the equator and the $\mathrm{SH}$ Hadley cell variability is larger then in the $\mathrm{NH}$, during MAM the ITCZ lies south of the equator and the NH Hadley cell variability is larger then in the $\mathrm{SH}$.
Another hemispheric difference in the Hadley cell strength also appears in the Hadley cell strength response to anthropogenic emissions. While the NH Hadley cell is projected to weaken by the end of this century, the SH Hadley cell strength does not exhibit any significant changes in response to increasing greenhouse gases $^{8}$. Unlike the role of dynamic ocean coupling, reported here, in driving the large hemispheric differences in the Hadley cell variability, dynamic coupling was found to reduce the projected weakening of the $\mathrm{NH}$ Hadley cell ${ }^{11}$, which thus reduces the discrepancy between the $\mathrm{NH}$ and $\mathrm{SH}$ Hadley cell strength responses to anthropogenic emissions. Other processes, then dynamic ocean coupling, should thus explain the different future response in the Hadley cell strength in the two hemispheres.

Finally, while here we focus on the effect of ocean coupling on the variability of the Hadley cell strength in the two hemispheres, ocean coupling might also be important for the different variability of the Hadley cell width in the $\mathrm{NH}$ and $\mathrm{SH}$. Unfortunately, unlike for the strength of the Hadley cell, one could not use the CESM's hierarchy of ocean experiments to examine the role of ocean coupling in the variability of the Hadley cell width since the hemispheric difference in the Hadley cell width in CESM is an outlier within the CMIP5 models. The hemispheric differences in the Hadley cell width variability in CESM are larger than the hemispheric differences in most (26) CMIP5 models, and is 2.7 times larger than the CMIP5 mean value. Thus, the importance of ocean coupling in the Hadley cell strength variability, reported here, would hopefully motivate other modeling centers to construct such hierarchy of preindustrial ocean coupling experiments, which would allow one to isolate the role of ocean coupling in the variability of the Hadley cell width.

\section{METHODS}

\section{Hadley cell strength}

We define the Hadley cell using the meridional mass stream function $(\Psi)$,

$\Psi(\phi, p)=\frac{2 \pi a \cos \phi}{g} \int_{0}^{p} \bar{v}(\phi, p) d p^{\prime}$,

where $\bar{v}$ is the zonal and annual mean meridional wind, $p$ is pressure, $\phi$ is latitude, and $a$ and $g$ are Earth's radius and gravity. The Hadley cell strength is defined as the maximum of the absolute value of $\psi$ at $500 \mathrm{mb}$ at each hemisphere $\left(\Psi_{\max }\right)$. Note that we choose to analyze the variability of the Hadley cell using $\Psi_{\max }$ (i.e., at a specific location) since the large hemispheric differences in the variability of the Hadley cell are evident across the tropics (Supplementary Fig. 1).

\section{Reanalyses}

To assess the interannual variability of the Hadley cell strength over recent decades, we use 1979-2017 $\bar{v}$ from four different reanalyses: the ECMWF Era-Interim ${ }^{41}$, NCEP/DOE Reanalysis $~ I I^{42}$, MERRA-2 (available from 1980) ${ }^{43}$, and CFSR V2 ${ }^{44}$. 


\section{CMIP5 models}

We also analyze the output from 30 climate models from the Coupled Model Intercomparison Project Phase 5 (CMIP5) $^{45}$ (using the ' $r 1 i 1 p 1^{\prime}$ realization), forced by the Historical and Representative Concentration Pathway 8.5 (RCP8.5) radiative forcings (Supplementary Table 1).

\section{Hierarchy of ocean coupling simulations}

To investigate the effect of ocean coupling and its different components on the hemispheric difference in the interannual variability of the Hadley cell strength, we follow previous studies ${ }^{11,28,29}$ and examine the different processes that affect the oceanic mixed-layer temperature. Namely, the surface heat fluxes (SHF), which account for the net heat flux into the ocean (thermodynamic coupling), and ocean heat flux convergence (OHFC, dynamic coupling). In particular, we conduct an attribution analysis, and analyze a set of three multi-century preindustrial control simulations with constant 1850 forcing, using the CESM, which only differ in their ocean coupling processes. Unlike the above datasets (reanalyses and the CMIP5 runs), the long preindustrial simulations not only allow us to gather enough statistics on the interannual variability of the Hadley cell strength, but also to examine only the internal variability of the circulation, as the transient external forcing is absent.

The first simulation (of 1800 years) is part of the CESM large-ensemble project ${ }^{30}$, and uses the full configuration of CESM (atmosphere, ocean, land, and sea-ice components have horizontal resolution of $\sim 1^{\circ}$ ) (referred to as FULL); in this configuration, both thermodynamic and dynamic coupling are active. In the second simulation (of 900 years), which is also part of the CESM large-ensemble project, the full-physics ocean of CESM is replaced by a slab-ocean model (referred to as SOM). In this configuration, while interannual variability of thermodynamic coupling (i.e., the heat flux exchange between the atmosphere/sea-ice and the ocean, SHF) is active (as in the full configuration), interannual variability of dynamic ocean coupling (horizontal and vertical OHFC changes) is inactive. The OHFC and mixed-layer depth in the slab ocean are fixed at their preindustrial values, calculated from the FULL preindustrial run, using the net heat flux into the mixed-layer (from both atmosphere and sea-ice) ${ }^{46}$. Thus, one can infer the role of OHFC in the interannual variability of the Hadley cell by comparing the circulation's variability in the FULL and SOM simulations. Note that the interannual variability of the mixed-layer depth account for changes in vertical mixing, and thus, it is part of the OHFC variability.

In the third simulation (of 500 years), there is no active ocean model (referred to as NOM), as the sea surface temperature in the slab-ocean model is fixed at its preindustrial values, calculated again from the FULL preindustrial run. Thus, comparing the interannual variability of the Hadley cell in the FULL and NOM simulations isolates the net role of ocean coupling (both thermodynamic and dynamic coupling) in the circulation's variability (note that unlike in atmosphere-only runs, in NOM, only the sea surface temperature is prescribed, while sea-ice is active). Furthermore, comparing the interannual variability of the circulation in the SOM and NOM runs allows one to infer the role of thermodynamic coupling in the interannual variability of the Hadley cell. Note that the above hierarchy of ocean coupling experiments assumes that the impacts of ocean coupling are linearly additive.

Before comparing the interannual variability of the Hadley cell strength in the FULL, SOM, and NOM runs, it is important to ensure that they all have similar preindustrial Hadley cell climatology, such that the different interannual variability across the runs is only due to the different ocean coupling processes and not due to different background states. Since the prescribed OHFC and mixed-layer depth in SOM, as well as the sea surface temperature in NOM, are calculated from the FULL run, the climatological Hadley cell, averaged over all years in each simulation, is very similar across the FULL, SOM, and NOM runs (Supplementary Fig. $2 \mathrm{a}-\mathrm{c}$ ). This provides us the confidence to use these simulations to examine the role of ocean coupling in the hemispheric differences in the interannual variability of the Hadley cell strength.

Lastly, it is important to verify that the FULL, SOM, and NOM runs are sufficiently long to capture the variability of the Hadley cell strength. Supplementary Fig. $2 \mathrm{~d}-\mathrm{f}$ shows the variance $\left(\sigma^{2}\right)$ in the Northern (blue) and Southern (red) Hemispheres Hadley cell strength, calculated over a different number of years (using 1000 random samples for each number of years), relative to the variance across the entire simulation. The variance of the Northern (Southern) Hemisphere Hadley cell does not change by more than $2 \%$ after $13(9), 29(36)$, and 18 (17) years in the FULL, SOM, and NOM simulations, respectively. Thus, these multi-century control runs are sufficiently long to capture the variability of the Hadley cell.

\section{GISS Model E2.1}

To validate that the role of OHFC in the variability of the Hadley cell in the two hemispheres in CESM does not depend on the specific formulations of CESM, we also analyze "fixed" OHFC experiments using the NASA Goddard Institute for Space Studies Model E2.1 (GISS Model E2.1) ${ }^{47}$. As in the preindustrial runs in CESM, we make use of the last 40 years of 150-year and 60-year preindustrial runs of the fully-coupled and slab ocean (with fixed OHFC and mixed-layer depth) configurations of the GISS Model E2.1, respectively.

\section{The Kuo-Eliassen equation}

To investigate via which processes ocean coupling modulates the interannual variability of the Hadley cell strength, we follow previous studies ${ }^{8,11,34}$, and analyze the Kuo-Eliassen (KE) equation. The KE equation derived based on quasigeostrophic assumptions, is a secondorder linear partial differential equation for $\psi^{48}$, and can be written as follows,

$$
\begin{gathered}
f^{2} \frac{g}{2 \pi a \cos \phi} \frac{\partial^{2} \psi}{\partial p^{2}}+S^{2} \frac{g}{2 \pi a} \frac{\partial}{a \partial \phi} \frac{1}{a \cos \phi} \frac{\partial \psi}{\partial \phi}=\frac{R}{p}\left(\frac{1}{a} \frac{\partial \bar{Q}}{\partial \phi}-\frac{\partial}{a \partial \phi} \frac{1}{a \cos \phi} \frac{\partial \overline{v^{\prime} T^{\prime}} \cos \phi}{\partial \phi}\right) \\
+f\left(\frac{1}{a \cos ^{2} \phi} \frac{\partial^{2} \overline{u^{\prime} v^{\prime} \cos } \operatorname{s}^{2} \phi}{\partial p \partial \phi}-\frac{\partial \bar{X}}{\partial p}\right),
\end{gathered}
$$

where $f$ is the Coriolis parameter, $S^{2}=-\frac{1}{\rho \theta} \frac{\partial \theta}{\partial p}$ is static stability, $\rho$ is density, $\theta$ is potential temperature, $R$ is the gas constant of dry air, $Q=Q_{\text {lat }}+Q_{\text {rad }}$ is diabatic heating, $Q_{\text {lat }}$ and $Q_{\text {rad }}$ are latent and radiative heating, respectively, $\overline{v^{\prime} T^{\prime}}$ and $\overline{u^{\prime} v^{\prime}}$ are eddy heat and momentum fluxes, respectively, $X$ is zonal friction (estimated from the annual and zonal mean zonal momentum quasigeostrophic equation) and primes represent deviation from zonal and monthly means. A solution for $\psi$ is achieved by numerically solving Equation (2) using the annual mean values of the righthand side terms and static stability. Note that since the KE equation comprises key components that control the Hadley cell, and since we allow $f^{2}$ and $S^{2}$ to vary spatially, the KE equation is able to capture the variability of the tropical circulation, in spite of being derived based on quasigeostrophic assumptions. Lastly, note that as pointed out in previous studies ${ }^{31,32}$, on sufficiently long timescales (i.e., when the time derivative of the zonal wind and temperature is small), the different righthand side terms in Equation (2) are not independent. Thus, the contribution of each term to changes in $\psi$ might stem from changes in the other terms in the equation. In particular, the effects of each term in the KE equation on the mean circulation might merely reinforce the effects of eddy flux since over long timescales the mean meridional flow in the zonal momentum equation is affected by eddy momentum flux and friction ${ }^{35}$.

\section{DATA AVAILABILITY}

The data used in the manuscript is publicly available for CMIP5 data (https://esgfnode.llnl.gov/projects/cmip5/), CESM data (http://www.cesm.ucar.edu and rei.chemke@weizmann.ac.il), NCEP (https://psl.noaa.gov/), ERA-I (https://www.ecmwf.int), CFSR and MERRA (http://rda.ucar.edu/ and https://esgf.nccs.nasa.gov/projects/create-ip/).

\section{CODE AVAILABILITY}

Any codes used in the manuscript are available upon request from rei. chemke@weizmann.ac.il.

Received: 28 June 2021; Accepted: 6 December 2021; Published online: 10 January 2022

\section{REFERENCES}

1. Lu, J., Vecchi, G. A. \& Reichler, T. Expansion of the hadley cell under global warming. Geophys. Res. Lett. 34, L06805 (2007).

2. Stocker, T. F. et al. Climate Change 2013: The Physical Science Basis. Contribution of Working Group I to the Fifth Assessment Report of the Intergovernmental Panel on Climate Change pp 1535 (Cambridge Univ. Press, 2013).

3. Waugh, D. W. et al. Revisiting the relationship among metrics of tropical expansion. J. Clim. 31, 7565-7581 (2018).

4. Chemke, R. \& Polvani, L. M. Exploiting the abrupt 4 xco 2 scenario to elucidate tropical expansion mechanisms. J. Clim. 32, 859-875 (2019).

5. Zhang, G. \& Wang, Z. Interannual variability of the atlantic hadley circulation in boreal summer and its impacts on tropical cyclone activity. J. Clim. 26, 8529-8544 (2013). 
6. Donohoe, A., Marshall, J., Ferreira, D., Armour, K. \& McGee, D. The interannual variability of tropical precipitation and interhemispheric energy transport. J. Clim. 27, 3377-3392 (2014).

7. Zhang, G. \& Wang, Z. Interannual variability of tropical cyclone activity and regional Hadley circulation over the Northeastern Pacific. Geophys. Res. Lett. 42, 2473-2481 (2015).

8. Chemke, R. \& Polvani, L. M. Elucidating the mechanisms responsible for hadley cell weakening under 4xco2 forcing. Geophys. Res. Lett. 48, e2020GL090348 (2021).

9. Clement, A. C. The role of the ocean in the seasonal cycle of the hadley circulation. J. Atmos. Sci. 63, 3351-3365 (2006).

10. Chemke, R. \& Polvani, L. M. Ocean circulation reduces the Hadley cell response to increased greenhouse gases. Geophys. Res. Lett. 45, 9197-9205 (2018).

11. Chemke, R. Future changes in the hadley circulation: the role of ocean heat transport. Geophys. Res. Lett. 48, e2020GL091372 (2021).

12. Tomas, R. A., Deser, C. \& Sun, L. The role of ocean heat transport in the global climate response to projected arctic sea ice loss. J. Clim. 29, 6841-6859 (2016).

13. Wang, K., Deser, C., Sun, L. \& A., T. R. Fast response of the tropics to an abrupt loss of arctic sea ice via ocean dynamics. Geophys. Res. Lett. 45, 4264-4272 (2018).

14. Chemke, R., Polvani, L. M. \& Deser, C. The effect of arctic sea ice loss on the hadley circulation. Geophys. Res. Lett. 46, 963-972 (2019).

15. Lu, J., Chen, G. \& Frierson, D. M. W. Response of the zonal mean atmospheric circulation to El Niño versus global warming. J. Clim. 21, 5835 (2008).

16. Lucas, C. \& Nguyen, H. Regional characteristics of tropical expansion and the role of climate variability. J. Geophys. Res. 120, 6809-6824 (2015).

17. Allen, R. J. \& Kovilakam, M. The role of natural climate variability in recent tropical expansion. J. Clim. 30, 6329-6350 (2017).

18. Amaya, D. J., Siler, N., Xie, S. \& Miller, A. J. The interplay of internal and forced modes of Hadley Cell expansion: lessons from the global warming hiatus. Clim. Dyn. 51, 305-319 (2018).

19. Oort, A. H. \& Yienger, J. J. Observed interannual variability in the hadley circulation and its connection to ENSO. J. Clim. 9, 2751-2767 (1996).

20. Seager, R., Harnik, N., Kushnir, Y., Robinson, W. \& Miller, J. Mechanisms of Hemispherically Symmetric Climate Variability. J. Clim. 16, 2960-2978 (2013).

21. Ma, J. \& Li, J. The principal modes of variability of the boreal winter Hadley cell. Geophys. Res. Lett. 35, L01808 (2008).

22. Nguyen, H., Evans, A., Lucas, C., Smith, I. \& Timbal, B. The hadley circulation in reanalyses: climatology, variability, and change. J. Clim. 26, 3357-3376 (2013).

23. Sun, Y. \& Zhou, T. How does El Niño affect the interannual variability of the boreal summer hadley circulation? J. Clim. 27, 2622-2642 (2014).

24. Sun, Y. et al. Regional meridional cells governing the interannual variability of the Hadley circulation in boreal winter. Clim. Dyn. 52, 831-853 (2019).

25. Caballero, R. Role of eddies in the interannual variability of Hadley cell strength. Geophys. Res. Lett. 34, L22705 (2007).

26. Zurita-Gotor, P. \& Álvarez-Zapatero, P. Coupled interannual variability of the hadley and ferrel cells. J. Clim. 31, 4757-4773 (2018).

27. Tanaka, H. L., Ishizaki, N. \& Kitoh, A. Trend and interannual variability of Walker, monsoon and Hadley circulations defined by velocity potential in the upper troposphere. Tellus 56, 250-269 (2004).

28. Deser, C., Sun, L., Tomas, R. A. \& Screen, J. Does ocean coupling matter for the northern extratropical response to projected Arctic sea ice loss? Geophys. Res. Lett. 43, 2149-2157 (2016).

29. Chemke, R., Polvani, L. M., Kay, J. E. \& C., O. Quantifying the role of ocean coupling in arctic amplification and sea-ice loss over the 21 st century. npj Clim. Atmos. Sci. 3, 46 (2021)

30. Kay, J. E. et al. The community earth system model (CESM) large ensemble project: a community resource for studying climate change in the presence of internal climate variability. Bull. Am. Meteor. Soc. 96, 1333-1349 (2015).

31. Chang, E. K. M. Mean meridional circulation driven by eddy forcings of different timescales. J. Atmos. Sci. 53, 113-125 (1996).

32. Kim, H.-K. \& Lee, S. Hadley cell dynamics in a primitive equation model. Part II: nonaxisymmetric flow. J. Atmos. Sci. 58, 2859-2871 (2001)

33. Kim, H.-K. \& Lee, S. Hadley cell dynamics in a primitive equation model. Part I: axisymmetric flow. J. Atmos. Sci. 58, 2845-2858 (2001).

34. Chemke, R. \& Polvani, L. M. Opposite tropical circulation trends in climate models and in reanalyses. Nat. Geosci. 12, 528-532 (2019).

35. Vallis, G. K. Atmospheric and Oceanic Fluid Dynamics pp. 770 (Cambridge University Press, Cambridge, U.K., 2006).

36. Schott, F. A., Xie, S. P., \& McCreary, J. P. Indian ocean circulation and climate variability. Rev. Geophys. 47, RG1002 (2009).
37. Schwendike, J. et al. Local partitioning of the overturning circulation in the tropics and the connection to the hadley and walker circulations. J. Geophys. Res. 119, 1322-1339 (2014).

38. Staten, P. W., Grise, K. M., Davis, S. M., Karnauskas, K. \& Davis, N. Regional widening of tropical overturning: Forced change, natural variability, and recent trends. J. Geophys. Res. 124, 6104-6119 (2019).

39. Raiter, D., Galanti, E. \& Kaspi, Y. The tropical atmospheric conveyor belt: A coupled eulerian-lagrangian analysis of the large-scale tropical circulation. Geophys. Res. Lett. 47, e2019GL086437 (2020).

40. Bjerknes, J. Atmospheric teleconnections from the equatorial pacific. Mon. Weath. Rev. 97, 163-172 (1969).

41. Dee et al., D. P. The ERA-Interim reanalysis: configuration and performance of the data assimilation system. Q. J. R. Meteorol. Soc. 137, 553-597 (2011).

42. Kanamitsu, M. et al. Ncep-doe amip-ii reanalysis (r-2). Bull. Am. Meteor. Soc. 83, 1631-1643 (2002).

43. Gelaro et al., R. The modern-era retrospective analysis for research and applications, version 2 (MERRA-2). J. Clim. 30, 5419-5454 (2017).

44. Saha, S. et al. The NCEP climate forecast system version 2. J. Clim. 27, 2185-2208 (2014).

45. Taylor, K. E., Stouffer, R. J. \& Meehl, G. A. An overview of CMIP5 and the experiment design. Bull. Am. Meteor. Soc. 93, 485-498 (2012).

46. Bitz, C. M. et al. Climate sensitivity of the community climate system model, version 4. J. Clim. 25, 3053-3070 (2012).

47. Kelley, M. et al. GISS-E2.1: Configurations and climatology. J. Adv. Mod. Earth Syst. 12, e2019MS002025 (2020).

48. Peixoto, J. P. \& Oort, A. H. Physics of Climate. (American Institute of Physics, 1992).

\section{ACKNOWLEDGEMENTS}

R. C. is grateful to Clara Orbe for the NASA GISS data, and for the support by the Israeli Science Foundation (Grant 906/21).

\section{AUTHOR CONTRIBUTIONS}

R. C. downloaded and analyzed the data and wrote the paper.

\section{COMPETING INTERESTS}

The author declares no competing interests.

\section{ADDITIONAL INFORMATION}

Supplementary information The online version contains supplementary material available at https://doi.org/10.1038/s41612-021-00225-3.

Correspondence and requests for materials should be addressed to Rei Chemke.

Reprints and permission information is available at http://www.nature.com/ reprints

Publisher's note Springer Nature remains neutral with regard to jurisdictional claims in published maps and institutional affiliations.

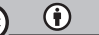

Open Access This article is licensed under a Creative Commons Attribution 4.0 International License, which permits use, sharing, adaptation, distribution and reproduction in any medium or format, as long as you give appropriate credit to the original author(s) and the source, provide a link to the Creative Commons license, and indicate if changes were made. The images or other third party material in this article are included in the article's Creative Commons license, unless indicated otherwise in a credit line to the material. If material is not included in the article's Creative Commons license and your intended use is not permitted by statutory regulation or exceeds the permitted use, you will need to obtain permission directly from the copyright holder. To view a copy of this license, visit http://creativecommons. org/licenses/by/4.0/.

(c) The Author(s) 2022 